\title{
Yumurtacı Tavuklarda Yumurta Verim Eğrilerinin Modellenmesi
}

Emin YALÇINÖZ ${ }^{1}$, Mustafa ŞAHİN ${ }^{\infty}$

${ }^{1}$ Kahramanmaraş Sütçü İmam Üniversitesi Ziraat Fakültesi, Zootekni Bölümü, Kahramanmaraş, ${ }^{21}$ Kahramanmaraş Sütçü İmam Üniversitesi

Ziraat Fakültesi, Tarımsal Biyoteknoloji Bölümü Kahramanmaraş

${ }^{1}$ https://orcid.org/0000-0002-9195-7793, ${ }^{2}$ https://orcid.org/0000-0003-3622-4543,

$\bowtie:$ ms66@edu.tr

\section{ÖZET}

$\mathrm{Bu}$ çalışmada yumurtacı tavuklarda yumurta verim eğrilerinin modellenmesinde kullanılan bazı modeller karşılaştırmalı olarak incelenmiştir. Bu amaçla Nick Brown ve Leghorn irkı tavukların 18. haftadan 59. haftaya kadar olan haftalık yumurta verimleri kullanılmıştır. Modelleme çalışmasında yaygın olarak kullanılan iki farklı kubik parçalı regresyon (iki ve üç boğumlu), lojistik, MMF, gamma, McNally, modifiye compartmental ve kuadratik parçalı regresyon modelleri ele alınmıştır. Modellerin karşılaştırılmasında ise hata kareler ortalamaları, belirleme katsayısı, düzeltilmiş belirleme katsayısı, akaike bilgi kriteri ve durbin-watson otokorelasyon değerleri kullanılmıştır. Çalışma sonucunda her iki ırktada en iyi sonuçlar modifiye compartmental modelinden elde edilmiştir (Nick Brown; HKO $=0.000007, \mathrm{R}^{2}=0.9999, \overline{\mathrm{R}}^{2}=0.9998, \mathrm{AIC}=-$ 392.966, DW=1.345: Leghorn; $\mathrm{HKO}=0.0001, \mathrm{R}^{2}=0.9998, \overline{\mathrm{R}}^{2}=0.9997$, $\mathrm{AIC}=-373.225, \mathrm{DW}=1.845)$. Kuadratik parçalı regresyonun ise incelenen modeller içerisinde en kötü sonuçlara sahip olduğu belirlenmiştir (Nick Brown; HKO=0.0007, $\mathrm{R}^{2}=0.9486, \overline{\mathrm{R}}^{2}=0.9412$ $\mathrm{AIC}=-298.257, \quad \mathrm{DW}=2.341$ : Leghorn; $\mathrm{HKO}=0.0002, \quad \mathrm{R}^{2}=0.9787$, $\left.\overline{\mathrm{R}}^{2}=0.9776, \mathrm{AIC}=-340.824, \mathrm{DW}=2.171\right)$.

\section{Modeling of Egg Production Curves in Poultry}

\section{ABSTRACT}

In this study, some models used in the modeling of egg yield curves in laying hens were examined comparatively. For this purpose, the weekly egg yields of Nick Brown and Leghorn chickens from 18th to 59th weeks were used. In the modeling study, two widely used cubic segment regression (two and three node), logistic, MMF, gamma, McNally, modified compartmental and quadratic segment regression models were discussed. In the comparison of the models, mean square error, coefficient of determination, corrected coefficient of determination, acoustic information criterion and durbin-watson autocorrelation values were used. As a result of the study, the best results were obtained from the modified compartmental model in both races (Nick Brown; HKO $=0.000007, \mathrm{R} 2=0.9999, \overline{\mathbf{R}}^{2}=0.9998, \mathrm{AIC}=-$ 392.966, DW=1.345: Leghorn; HKO $=0.0001, \mathrm{R} 2=0.9998, \overline{\mathbf{R}}^{2}=0.9997$, $\mathrm{AIC}=-373.225, \mathrm{DW}=1.845)$. The quadratic segment regression has the worst results among the examined models (Nick Brown; HKO $=0.0007$, $\mathrm{R} 2=0.9486, \quad \overline{\mathbf{R}}^{2}=0.9412 \quad \mathrm{AIC}=-298.257, \quad \mathrm{DW}=2.341$ : Leghorn; $\left.\mathrm{HKO}=0.0002, \mathrm{R} 2=0.9787, \overline{\mathbf{R}}^{2}=0.9776, \mathrm{AIC}=-340.824, \mathrm{DW}=2.171\right)$.

\section{Araştırma Makalesi}

\author{
Makale Tarihçesi \\ Geliş Tarihi : 19.02 .2020
}

Kabul Tarihi : 09.04.2020

Anahtar Kelimeler

Yumurta verimi

Eğri

Modelleme

\section{Research Article}

$\begin{array}{ll}\text { Article History } \\ \text { Received } & : 19.02 .2020 \\ \text { Accepted } & : 09.04 .2020\end{array}$

Keywords

Egg yield

Curve

Modeling

To Cite : Yalçıöz E, Şahin M 2020. Yumurtacı Tavuklarda Yumurta Verim Eğrilerinin Modellenmesi. KSÜ Tarım ve Doğa Derg 23 (5): 1373-1378. DOI: 10.18016/ksutarimdoga.vi.691069.

\section{GİRIŞ}

Yumurta üretimi gen, bakım ve beslenme gibi birçok faktörün etken olduğu karmaşı bir süreçtir. Bunun sonucu olarak üretilen yumurta miktarı üzerinde ırk, yaş, kuluçka, tüy dökme,beslenme, ve diğer çevresel faktörlerin etkisi oldukça yüksektir. Ancak, bu faktörler hangi düzeyde olursa olsun yumurta verim eğrileri genellikle benzerdir.

Yumurta verim eğrileri, üretilen yumurta sayısı ve belli bir zaman periyodu arasındaki fonksiyonel 
ilişkiyi ortaya koyar (Yang ve ark., 1989). Doğrusal, kuadratik ve kubik modellerin yanında doğrusal olmayan (nonlinear) modeller de yumurta verim eğrilerinin modellenmesinde yaygın olarak kullanılmaktadır (Casonve Ware, 1990; Miyoshi ve ark., 1996; Narushin ve Takma, 2003; Savegnago ve ark., 2011). Literatürde etlik piliç büyüme eğrilerinin modellenmesine göre yumurta verim eğrilerinin modellenmesi oldukça azdır. Yumurta verimlerinin elde edilme sürecinin büyüme parametrelerinin elde edilmesine göre oldukça uzun süre alması en önemli sebeptir. Yumurta üretimi cinsel olgunluk ile başlar, hızlı bir artışla zirveye ulaşır ve bir süre sonra azalan doğrusal bir eğilim izler.

Yumurta verim eğrilerinin modellenmesi, sürüye ait yumurta veriminin erken dönemde tahmini ve damızlık sürülerin oluşturulması amacıyla kullanılmaktadır. Özellikle amaç damızlık sürünün oluşturulması ise bireysel yumurta verim eğrilerinin modellenmesi önem arz etmektedir. Zira genetik kapasitesi yüksek bireylerin seçimi sürü bazında modelleme ile mümkün olamamaktadır.

Yumurta verim eğrilerinin birey yada sürü bazında modellenebilmesi için farklı matematiksel modeller uygulanmış ve geliştirilmiştir. Bazı araştırmacılar sürü bazında modellemede lojistik, eğrisel, doğrusal, üstel, polinomiyal, ve bölünmüş polinomiyaller gibi farklı yaklaşımları kullanmışlardır. Diğer yandan, bireysel yumurta verim eğrilerininyumurta üretim biyolojisinin daha anlaşılır olması açısından modellenmesinin önemi üzerinde çalışan araştırıcılar da olmuştur (Gavora ve ark., 1971;McMillan, 1981; Koops ve Grossman, 1992;Grossman ve ark., 2000;Grossman ve Koops, 2001,).

Yumurta verim eğrilerinin modellenmesi süreci laktasyon ve büyüme eğrilerinde olduğu gibi, gelişen bilgisayar teknolojileri ve hesaplama teknikleri göz önüne alındığında ucu açık ve süreklilik arz eden bir süreçtir.

\section{MATERYAL VE METOT}

Bu çalışmada Kahramanmaraş ilinde faaliyet gösteren iki ayrı firmadan temin edilen Nick Brown ve Leghorn ırkına ait veri seti kullanılmıştır. Her iki ırktanda 25000 adetlik kümesten alınan, 18. haftadan 59. haftaya kadar olan haftalık yumurta verimleri dikkate alınmış ve yumurta verim eğrilerinin modellenmesinde oransal verim değerleri (haftalık oransal verim=yumurta verimi/toplam birey sayısı) kullanılmıştır.

$\mathrm{Bu}$ çalışmada yumurtacı tavuklarda yumurta verim eğrilerinin modellenmesinde kullanılan eşitlikler kubik parçalı regresyon (iki ve üç boğumlu), lojistik, MMF (Çadırcı ve Koncagül, 2013), gamma (Wood), McNally (Demir ve ark., 2017), modifiye compartmental (Narinç ve ark., 2014) ve kuadratik parçalı regresyon modelleridir. Eğri grafikleri ve model parametre tahminleri SAS paket programinda yapılmıştır (SAS, 2011).Bu modellere ait eşitlikler ve açılımları aşağıdaki gibidir.

İki boğumlu kubikparçalı regresyon;

$W_{t}=\beta_{0}+\beta_{1} t+\beta_{2} t^{2}+\beta_{3} t^{3}+\beta_{4}(t-a)^{3}+\beta_{5}(t-b)^{3}$,

Üç boğumlu kubikparçalı regresyon;

$W_{t}=\beta_{0}+\beta_{1} t+\beta_{2} t^{2}+\beta_{3} t^{3}+\beta_{4}(t-a)^{3}+\beta_{5}(t-b)^{3}+$ $\beta_{6}(t-c)^{3}$,

Lojistik; $W_{t}=\beta_{0} /\left(1+\beta_{1} \mathrm{e}\left(-\beta_{2} t\right)\right)$,

MMF; $W_{t}=\left(\beta_{0} \beta_{1}+\beta_{2} t^{\beta_{3}}\right) /\left(\beta_{1}+t^{\beta_{3}}\right)$,

Gamma; $W_{t}=\beta_{0} t^{\beta_{1}} e^{\left(-\beta_{2} t\right)}$,

McNally; $W_{t}=$

$\beta_{0} t^{\beta_{1}} e^{\left(-\beta_{2} t+\beta_{3} t^{1 / 2}\right)}$,

Modifiye Compartmental;

$W_{t}=\beta_{0} e^{\left(-\beta_{1} t\right)} /\left(1+e^{-\beta_{2}\left(t-\beta_{3}\right)}\right.$,

Quadratic Spline; $W_{t}=\beta_{0}+\beta_{1} \mathrm{t}+\beta_{2} \mathrm{t}^{2}$,

şeklindedir. Burada, $\mathrm{W}_{\mathrm{t}}$ : t. gündeki yumurta verimini, $\beta_{0}, \beta_{1}, \beta_{2}, \beta_{3}, \beta_{4}, \beta_{5}$ ve $\beta_{6}$ : modeller için tanımlanan sabitleri,a ve $\mathrm{b}$; parçalı regresyonda boğum noktalarını,e: 2.7182,t: yaşı (hafta),ifade etmektedir.

$\mathrm{Bu}$ çalışmada yumurtacı tavuklarda yumurta verim eğrilerinin modellenmesinde kullanılan (kubik parçalı regresyon, lojistik, MMF, gamma, McNally, modifiye compartmental ve kuadratik parçalı regresyon) eşitliklerin noktasal dağılıma uygunluğunun karşılaştırılmasında belirleme katsayısı, düzeltilmiş belirleme katsayısı, hata kareler ortalaması, DurbinWatson ve AIC (Akaike Bilgi Kriteri) dikkate alınmıştır (Narinç ve ark., 2014).

Belirleme katsayısı (R2): Belirleme katsayısına ait eşitlik,

$R^{2}=1-(H K T / G K T)$, şeklindedir. Burada,HKT: Hata kareler toplamını,GKT: Genel kareler toplamını ifade eder.

Düzeltilmiş belirleme katsayısı $\left(\overline{\mathrm{R}}^{2}\right)$; Düzeltilmiş belirleme katsayısına ait eşitlik,

$\overline{\mathrm{R}}^{2}=1-\left[\frac{(n-1)}{(n-p)}\right] *\left(1-R^{2}\right)$, şeklindedir. Burada, $R^{2}$ : Belirleme katsayısını, $n$.Gözlem çifti sayısını, $p$ : Modeldeki parametre sayısını ifade eder.

$R^{2}$ değeri, oluşturulan eğri modelinin, veri setindeki toplam değişimin ne kadarlık bir kısmını ifade edebildiğinin bir ölçüsüdür ve $0 \leq R^{2} \leq 1$ aralığında değişim gösterir. Katsayısının yüksek oluşu, oluşturulan modelin noktasal dağılıma uygunluğunun yüksek olduğu anlamına gelir. Düzeltilmiş belirleme katsayısı ise eşitlik 3.8'den anlaşılacağı üzere örnek büyüklüğü dikkate alınarak hesaplanan belirleme katsayısını ifade eder ve her zaman belirleme katsayısından düşük bir değere sahiptir. 
Hata Kareler Ortalaması (HKO):Hata kareler ortalamasına ait eşitlik,

$H K O=H K T /(n-p)$, şeklindedir. Burada,HKO: Hata Kareler Ortalamasını,n: Gözlem Çifti Sayısını,p: Modeldeki Parametre Sayısını ifade etmektedir.

Akaike Bilgi Kriteri (AIC):Akaike bilgi kriteri modeller arasında istatistiksel olarak en uygun olanı seçmekte yaygın olarak kullanılan bir değerdir. Akaike bilgi kriteri değeri en küçük olan modelin en uygun model olduğu kabul edilir ve Akaike bilgi kriterine ait eşitlik, $A I C=n \times \ln \left(\frac{H K T}{n}\right)+2 k, \quad$ şeklindedir. Burada,HKT: Hata Kareler Toplamını,n: Gözlem Çifti Sayısını,k: Modeldeki Parametre Sayısını ifade etmektedir.

Durbin-Watson Otokorelasyon Testi (DW): Tahmin edilen modelde hata terimlerinin korelasyon halinde olup olmadığını test etmeye yarayan bir testtir. Bu testle elde edilen sayının 2 civarında çıkması otokorelasyon olmadığı anlamına gelir. Burada ei= hata terimi, $\mathrm{t}=$ zaman olmak üzere Durbin Watson test istatistiği,

$D W=\frac{\sum_{t=2}^{n}\left(e_{t}-e_{t-1}\right)^{2}}{\sum_{t=1}^{n} e_{t}^{2}}$, şeklinde yazılabilir. DW değeri her zaman 0 ila 4 arasında yer alır. DW değerinin 2 olması durumunda otokorelasyonun olmadığı kabul edilir.

\section{BULGULAR VE TARTIŞMA}

Yumurtacı tavuklarda yumurta verim eğrilerinin modellenmesinde elde edilen SAS 9.0 istatistik paket programı analiz sonuçları, iki farklı kubik parçalı regresyon, lojistik, MMF, gamma, McNally, modifiyecompartmental ve kuadratik parçalı regresyonmodelleri için iki farklı ırka ait hata kareler ortalamaları, belirleme katsayısı ,düzeltilmiş belirleme katsayısı, akaike bilgi kriteri ve durbinwatson otokorelasyon değerleri Çizelge 1 ve Çizelge 2' de verilmiştir.

Çizelge 1. Nick brown irkına ait hata kareler ortalamaları, belirleme katsayısı, düzeltilmiş belirleme katsayısı, Akaike bilgi kriteri ve Durbin-Watson otokorelasyon değerleri.

Table 1. The error squares mean, coefficient of determination, corrected coefficient of determination, Akaike information criterion and Durbin-Watson autocorrelation values of Nick brown race.

\begin{tabular}{|l|c|c|c|c|c|}
\hline \multicolumn{2}{|c|}{ Modeller } & \multicolumn{4}{c|}{ Nick Brown } \\
\cline { 2 - 6 } & HKO & $\mathbf{R}^{2}$ & $\overline{\mathbf{R}}^{\mathbf{2}}$ & \multicolumn{1}{c|}{ AIC } & DW \\
\hline Kubik Parçalı Regresyon (2 Boğumlu) (Cubic Spline) & 0.000128 & 0.9912 & 0.9900 & -367.511 & 1.987 \\
\hline Kubik Parçalı Regresyon (3 Boğumlu) (Cubic Spline) & 0.00126 & 0.9914 & 0.9900 & -366.369 & 1.817 \\
\hline Lojistik (Logistic) & 0.0007 & 0.9996 & 0.9984 & -298.257 & 2.153 \\
\hline MMF & 0.0009 & 0.9983 & 0.9980 & -290.834 & 2.319 \\
\hline Gamma & 0.006 & 0.9927 & 0.9914 & -210.399 & 2.447 \\
\hline McNally & 0.004 & 0.9945 & 0.9941 & -226.745 & 2.378 \\
\hline Modifiye Compartmental & 0.000007 & 0.9999 & 0.9998 & -392.966 & 1.945 \\
\hline Kuadratik Parçalı Regresyon (Quadratic Cubic Spline) & 0.0007 & 0.9486 & 0.9412 & -298.257 & 2.341 \\
\hline
\end{tabular}

Çizelge 2. Leghorn irkına ait hata kareler ortalamaları, belirleme katsayısı, düzeltilmiş belirleme katsayısı, Akaike bilgi kriteri ve Durbin-Watson otokorelasyon değerleri.

Table 2. Averages of error squares, determination coefficient, corrected determination coefficient, Akaike information criterion and Durbin-Watson autocorrelation values of Leghorn race.

\begin{tabular}{|c|c|c|c|c|c|}
\hline \multirow{2}{*}{ Modeller } & \multicolumn{5}{|c|}{ Leghorn } \\
\hline & HKO & $\mathrm{R}^{2}$ & $\overline{\mathbf{R}}^{2}$ & AIC & DW \\
\hline Kubik Parçalı Regresyon (2 Boğumlu) (Cubic Spline) & 0.0001 & 0.9870 & 0.9852 & -363.5084 & 2.331 \\
\hline Kubik Parçalı Regresyon (3 Boğumlu) (Cubic Spline) & 0.0001 & 0.9875 & 0.9857 & -363.064 & 2.279 \\
\hline Lojistik (Logistic) & 0.0002 & 0.9996 & 0.9995 & -349.293 & 2.105 \\
\hline MMF & 0.0013 & 0.9980 & 09978 & -275.806 & 1.759 \\
\hline Gamma & 0.0047 & 0.9927 & 0.9922 & -221.852 & 2.568 \\
\hline McNally & 0.0033 & 0.9949 & 0.9944 & -234.995 & 2.211 \\
\hline Modifiye Compartmental & 0.0001 & 0.9998 & 0.9997 & -373.225 & 1.985 \\
\hline Kuadratik Parçalı Regresyon (Quadratic Cubic Spline) & 0.0002 & 0,9787 & 0.9776 & -340.824 & 2.171 \\
\hline
\end{tabular}

Çizelge 1'de görüldüğü üzere kubik parçalı regresyon sonuçları hata kareler ortalaması, belirleme katsayısı, düzeltilmiş belirleme katsayısı, akaike bilgi kriteri ve Durbin-Watson otokorelasyon değerleri bakımından birbirine oldukça yakın değerler vermiştir. Diğer bir ifade ile boğum sayısındaki artış bu değerler üzerinde kayda değer bir değişim meydana getirmemiştir.
Belirleme katsayısı ve düzeltilmiş belirleme katsayısı bakımından incelendiğinde ise kuadratik parçalı regresyon dışındaki tüm modellerde 0.99 'un üzerinde olduğu görülmektedir. En iyi modelin modifiye compartmental $\quad\left(\mathrm{R}^{2}=0.9999, \quad \overline{\mathrm{R}}^{2}=0.9998\right)$, en kötü modelin ise kuadratik parçalı regresyon $\left(\mathrm{R}^{2}=0.9486\right.$, $\overline{\mathrm{R}}^{2}=0.9412$ ) olduğu görülmektedir. 
Akaike bilgi kriteri bakımından ise en düşük değerin modifiye compartmental modelde (AIC=-392.966) olduğu, buna en yakın değerlerin ise kubik parçalı regresyonlarda ( 2 boğumluda $\mathrm{AIC}=-367.511$ ve 3 boğumluda $\mathrm{AIC}=-366.369)$ olduğu görülmektedir. En yüksek akaike bilgi kriteri değeri ise gamma modeline aittir (AIC =-210.399).

Durbin-Watson otokorelasyon değerleri incelendiğinde hiçbir modelde otokorelasyon sıkıntısı olmadığı görülmektedir. Bununla birlikte en uygun değerin modifiye compartmental modelde (DW=1.945), en kötü değerin gamma modelinde $(\mathrm{DW}=2.447)$ ortaya çıktığ 1 görülmektedir.
Hata kareler ortalaması bakımından en iyi modelin modifiye compartmental model $\quad(\mathrm{HKO}=0.000007)$ olduğu, buna yakın değerler veren modellerin ise sırasıyla, iki boğumlu parçalı regresyon $(\mathrm{HKO}=0.000128)$, lojistik $(\mathrm{HKO}=0.0007)$ ve $\mathrm{MMF}$ $(\mathrm{HKO}=0.0009)$ modeli olduğu görülmektedir.

Nick Brown ırkı için, iki farklı kubik parçalı regresyon, lojistik, MMF, gamma, McNally, modifiye compartmental ve kuadratik parçalı regresyon modelleri için elde edilen yumurta verim eğrileri, tek bir grafikte eğrilerin birbirlerine göre konumlarının görülebilmesi açısından toplu olarak Şekil 1'de verilmiştir.

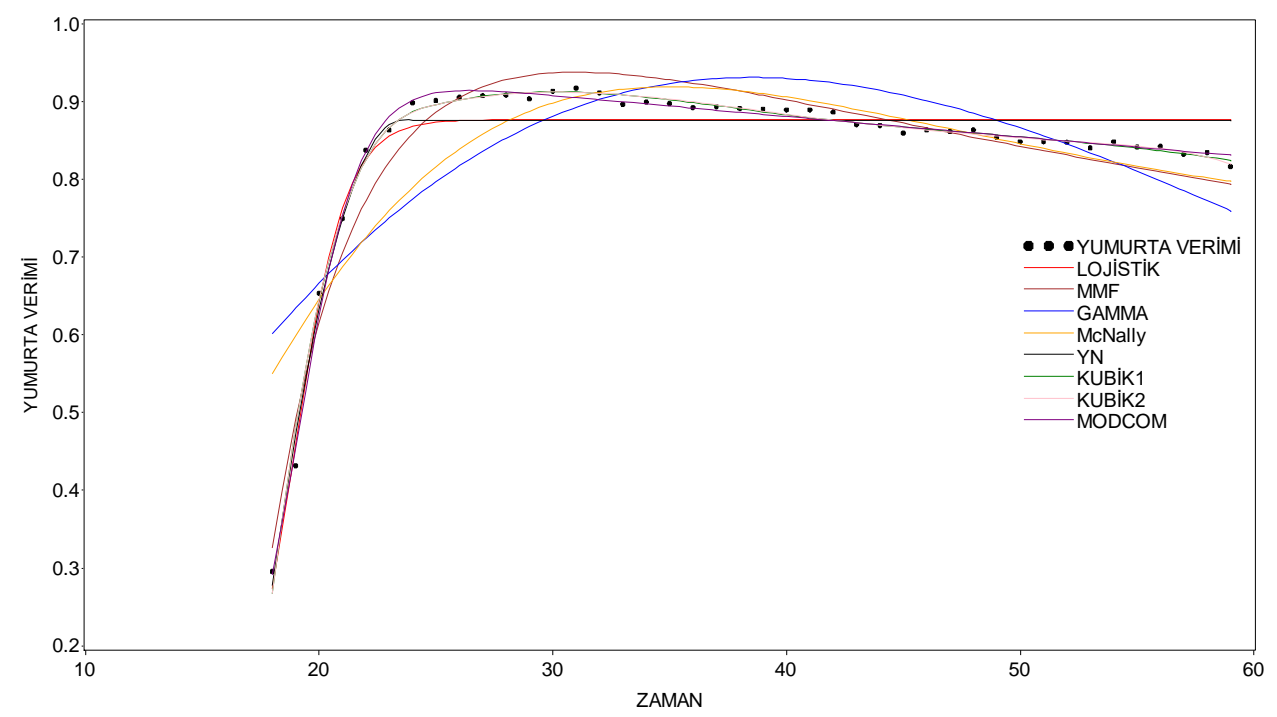

Şekil 1. Nick brown ırkı için, lojistik, mmf, gamma, mcnally, kuadratik parçalı regresyon iki farklı kubik parçalı regresyon ve modifiye compartmental eğrileri.

Figure 1. Logistics, mmf, gamma, mcnally, quadratic segmented regression for the brown race. Two different cubic segmented regression and modified compartmental curves.

Çizelge 2 incelendiğinde, kubik parçalı regresyon Nick Brown ırkında olduğu gibi sonuçları hata kareler ortalaması, belirleme katsayısı, düzeltilmiş belirleme katsayısı, akaike bilgi kriteri ve Durbin-Watson otokorelasyon değerleri bakımından birbirine çok yakın değerler vermiştir. Burada da Durbin-Watson otokorelasyon değerleri incelendiğinde hiçbir modelde otokorelasyon sıkıntısı olmadığı görülmektedir.

Belirleme katsayısı ve düzeltilmiş belirleme katsayısı bakımından incelendiğinde ise parçalı regresyonlar (2 boğumlu, 3 boğumlu ve kuadratik) dişında tüm modellerde 0.99'un üzerinde olduğu görülmektedir. En iyi modelin modifiye compartmental $\left(\mathrm{R}^{2}=0.9998\right.$, $\overline{\mathrm{R}}^{2}=0.9997$ ), en kötü modelin ise kuadratik parçalı regresyon $\left(\mathrm{R}^{2}=0.9787, \quad \overline{\mathrm{R}}^{2}=0.9776\right) \quad$ olduğu görülmektedir.

Akaike bilgi kriteri bakımından ise en düşük değerin modifiye compartmental modelde (AIC=-373.225) olduğu, buna en yakın değerlerin ise kubik parçalı regresyonlarda (2 boğumluda $\mathrm{AIC}=-363.5084 \mathrm{ve} 3$ boğumluda $\quad \mathrm{AIC}=-363.064) \quad$ ve lojistik
regresyonda(AIC= -349.293) olduğu görülmektedir. En yüksek akaike bilgi kriteri değeri ise yine gamma modeline aittir (AIC =-221.852).

Durbin-Watson otokorelasyon değerleri bakımından en uygun değerin modifiye compartmental modelde (DW=1.985), en kötü değerin gamma modelinde $(\mathrm{DW}=2.568)$ ortaya çıktığı görülmektedir. Hata kareler ortalaması bakımından en iyi modelin modifiye compartmental model, iki ve üç boğumlu parçalı regresyon modelleri olduğu $(\mathrm{HKO}=0.0001)$, en kötü modelin ise gamma $(\mathrm{HKO}=0.0047)$ olduğu görülmektedir.

Leghorn ırkı için, tüm modellere ait tahmin edilen eğrilerinbirbirlerine göre konumlarının görülebilmesi açısından toplu olarak Şekil 2'de verilmiştir.

Çizelge 1'de verilen Nick Brown ve Çizelge 2'de verilen leghorn irklarina ait hata kareler ortalaması, belirleme katsayısı, düzeltilmiş belirleme katsayısı ve akaike bilgi kriteri değerlerine bakıldığında en yetersiz sonuçların gamma modelinden elde edildiği görülmektedir. Bu sonuçları, her iki ırk için verilen 
gamma modeline ait Şekil 1 ve Şekil 2'teki eğrilerin noktasal dağılıma göre konumları görsel olarak desteklemektedir. Bu sonuç Anang ve Indrijani (2006),
Demir ve ark. (2017) ve Narinç ve ark. (2014)'nın bulmuş olduğu sonuçlarla uyum içerisindedir.

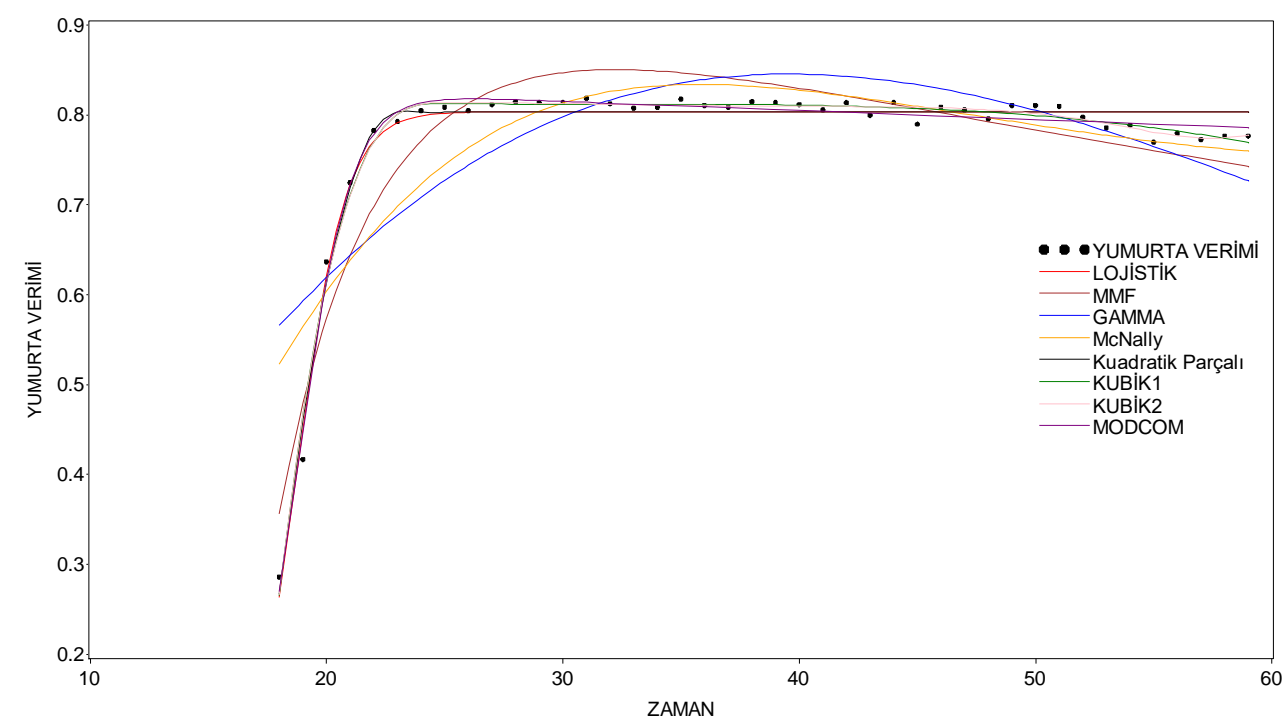

Şekil 2. Leghorn ırkı için, lojistik, mmf, gamma, mcnally, kuadratik parçalı regresyon iki farklı kubik parçalı regresyon ve modifiye compartmental eğrileri.

Figure 2. Logistic, mmf, gamma, mcnally, quadratic segment regression for the Leghorn race, two different cubic segment regression and modified compartmental curves.

Her iki ırkta da kuadratik parçalı regresyon diğer modellere göre karşılaştırma kriterleri bakımından oldukça kötü sonuçlar vermiş̧ir. Bunun nedeni,kuadratik parçalı regresyonda, yumurta verim eğrisinin maksimum noktaya ulaşıncaya kadar hızla artan veya kuadratik bir eğilim göstermesi ve maksimum noktadan sonra zamana bağlı olarak gittikçe azalan bir eğilim içerisine girmesidir. Çünkü kuadratik parçalı regresyonun tanımlamasında, maksimum noktaya ulaştıktan sonra zamana bağlı olarak yumurta veriminin sabitlendiği varsayılmıştır. Dolayısıyla yumurta verim kayitlarının uzaması (59. haftaya kadar) modeli maksimum noktaya ulaştıktan sonra zayıflatmaktadır.

Her iki ırkta da kubik parçalı regresyonda boğum sayısının arttırılması hata kareler ortalaması, belirleme katsayısı, düzeltilmiş belirleme katsayısı ve akaike bilgi bakımından düşük düzeyde iyileşmeye neden olmuştur. Kubik parçalı regresyonlar bakımından elde edilen sonuçlar Çadırcı ve Koncagül (2013)'ün çalışması ile uyum içerisindedir.

Her iki ırkta da kubik parçalı regresyon (iki ve üç boğumlu), lojistik, MMF, McNally ve modifiye compartmental modellere ait hata kareler ortalamaları, belirleme katsayısı, düzeltilmiş belirleme katsayısı, akaike bilgi kriteri ve DurbinWatson otokorelasyon değerleri bakımından birbirlerine çok yakın değerler elde edilmiştir. Bu sonuçlar Narushin ve Takma (2003), Anang ve Indrijani (2006), Miyoshi ve ark. (1996), Savegnago ve ark. (2012), Çadırcı ve Koncagül (2013), Narinç ve ark.
(2014) ve Bindya ve ark. (2010)'nın sonuçları ile uyum içerisindedir.

Her iki ırkta da hata kareler ortalaması, belirleme katsayısı, düzeltilmiş belirleme katsayısı, akaike bilgi kriteri ve Durbin-Watson değerleri bakımından elde edilen sonuçlar incelendiğinde en iyi modelin modifiye compartmental (Nick Brown; $\mathrm{HKO}=0.000007$, $\mathrm{R}^{2}=0.9999, \quad \overline{\mathrm{R}}^{2}=0.9998, \quad \mathrm{AIC}=-392.966, \quad \mathrm{DW}=1.345$ : Leghorn; HKO $=0.0001, \mathrm{R}^{2}=0.9998, \overline{\mathrm{R}}^{2}=0.9997$, AIC $=-$ 373.225, DW=1.845); en kötü modelin ise kuadratik parçalı regresyon olduğu (Nick Brown; HKO $=0.0007$, $\mathrm{R}^{2}=0.9486, \quad \overline{\mathrm{R}}^{2}=0.9412 \mathrm{AIC}=-298.257, \quad \mathrm{DW}=2.341$ : Leghorn; $\mathrm{HKO}=0.0002, \mathrm{R}^{2}=0.9787, \overline{\mathrm{R}}^{2}=0.9776, \mathrm{AIC}=-$ 340.824, DW=2.171) görülmüştür. Elde edilen bu sonuç Anang ve Indrijani (2006), Miyoshi ve ark. (1996) ve Narinç ve ark. (2014)'nın elde ettiği sonuçlar ile uyum içerisindedir (Yalçınöz, 2020).

\section{SONUÇ}

$\mathrm{Bu}$ çalışmada, hem Nick Brown hemde Leghorn yumurtacı ırklarında, yumurta verim eğrilerinin modellenmesinde en iyi modelin modifiye compartmental en kötü modelin ise kuadratik parçalı regresyon olduğu sonucuna varılmıştır.Bununla birlikte kubik parçalı regresyon (iki ve üç boğumlu), lojistik, MMF ve McNally modellerinin model karşılaştırma kriterleri bakımından modifiye compartmental modeline çok yakın değerler verdiği, gamma modelinin ise kuadratik modelden sonra en yetersiz model olduğu sonucuna varılmıştır.

Burada unutulmaması gereken konu farklı modellerin 
farklı veri setlerinde farklı sonuçlar üretebileceğidir. $\mathrm{Bu}$ nedenle gerek islah gerekse sezonluk yumurta veriminin tespiti amaçlı yapılan modellemelerde birden fazla modelin kullanılmasına ve modellerin biyolojik anlamda yorumlanabilir olmasina dikkat edilmelidir. Aynı zamanda model karşılaştırma kriterlerinin mümkün olduğunca fazla olması ve model seçiminde bu kriterlerin toplu olarak değerlendirilmesi araştırıcının istatistiksel anlamda en uygun modeli belirlemesine yardımcı olacaktır.

İşletmelerde sürü bazında yumurta verim eğrilerinin modellenmesinin, sürü yönetimi, bakım ve besleme koşulları gibi konulara yön vereceği düşünüldüğünde, modellemenin ne kadar önemli olduğu ortaya çıkmaktadır.

Özellikle ebeveyn sürü içerisinde genetik kapasitesi yüksek bireylerin seçiminde, sürü bazlı yumurta verim eğrilerinin araştırıcıya herhangi bir faydası yoktur. $\mathrm{Bu}$ nedenle bireysel yumurta verim kayitlarmin tutulması ve yumurta verim eğrilerinin bu kayıtlar üzerinden yapılması son derece önemlidir. Bu konuda çok az çalışma yapılmış olması yumurta verim sürecinin oldukça uzun olmasının bir sonucu olarak düşünülmektedir.

\section{TEŞEKKÜR}

Emin Yalçınöz'ün "Yumurtacı Tavuklarda Yumurta Verim Eğrilerinin Modellenmesi" isimli yüksek lisans tez çalışmasından özetlenmiştir.

Çıkar çatışması beyanı

Yazarlar arasında çıkar çatışması yoktur.

\section{Yazar Katkı Oranları}

Yazarlar makaleye eşit oranda katkı sağladıklarını beyan ederler.

\section{KAYNAKLAR}

Anang A, Indrijani H2006. Mathematical Models to Describe Egg Production in Laying Hens (Review) (Model Matematik untuk Menggambarkan Kurva Produksi Telur pada Ayam Petelur (Review). Jurnal Ilmu Ternak, Desember, 6(2): 91 - 95.

Bindya LA, Murthy HNN, Jayashankar MR, Govindaiah MG 2010. Mathematical Models for Egg Production in an Indian Colored Broiler Dam Line. International Journal of Poultry Science, 9 (9): 916919.

Cason JA, Ware GO 1990. Analysis of flock egg production curves using generalized growth functions. Poultry Science, 69: 1064-1069.

Çadırcı Ş, Koncagül S 2013. Effects of initial body weight and feed intake on individual weekly egg production curve of laying hens. Agric. Fac. HR.U., 17(1): 15-23.

Demir O, Macit M, Çelebi Ş, Esenbuğa N, Kaya H 2017. Yumurtacı Tavuk Rasyonlarına Değişik Oranlarda Katılan Humat'in Yumurta Verimine Etkisinin Gamma ve Mcnally Modelleri ile Analizi. Alinteri Journal of Agricultural Sciences, 32(2): 8186.

Gavora JS, Parker RJ, Mcmillan I 1971. Mathematical model of egg production. Poultry Science. 50: 13061315.

Grossman M, Koops WJ 2001. A model for individual egg production in chickens. Poultry Science, 80: 859-867.

Grossman M, Gossman TN, Koops WJ 2000. A model for persistency of egg production. Poultry Science, 79: $1715-1724$.

Koops WJ, Grossman M 1992. Characterization of poultry egg production using a multiphasic approach. Poultry Science, 71: 399-405.

Mcmillan I 1981. Compartmental model analysis of poultry egg production curves. Poultry Science, 60: 1549-1551.

Miyoshi S, Luc MK, Kuchida K, Mitsumoto T 1996. Application of Nonlinear Models to Egg Production Curves in Chickens. Jpn. Poultry Science, 33: 178184.

Narinç D, Üçkardeş F, Aslan E 2014. Egg production curve analyses in poultry science. World's Poultry Science Journal, 70(04): 817-828.

Narushin VG, Takma C 2003. Sigmoid model for the evaluation of growth and production curves in laying hens. Biosystems Engineering, 84: 343-348.

SAS Institute (2011) SAS/STAT User Guide. Version 9.3 edition. SAS Institute Inc.

Savegnago RP, Cruz VA, Ramos SB, Caetano SL, Schmidt GS, Ledur MC, El Faro L, Munari DP 2012. Egg production curve fitting using nonlinear models for selected and nonselected lines of White Leghorn hens. Poultry Science, 91: 2977-2987.

Yalçınöz E, 2020. Yumurtacı Tavuklarda Yumurta Verim Eğrilerinin Modellenmesi. Kahramanmaraş Sütçü İmam Üniversitesi, Fen Bilimleri Enstitüsü, $46 \mathrm{~s}$.

Yang N, Wu C, Mcmillan L 1989. A new mathematical model for poultry egg production. Poultry Science, 68: $476-481$. 